\title{
Dentists' perspective on preference for direct restorative materials for different tooth cavities: A study from two colleges in Kathmandu, Nepal
}

Paudel KR', Gautam S'2, Pokhrel P³, Raghubansi BR' ${ }^{4}$, Shrestha A' ${ }^{1}$, Raut B'

${ }^{1}$ Keshab Raj Paudel, Department of Pharmacology, Kathmandu Medical College Teaching Hospital, Kathmandu, Nepal; ${ }^{2}$ Suman Gautam, Department of Conservative Dentistry and Endodontics, Nepal Medical College Teaching Hospital, Kathmandu, Nepal; ${ }^{3}$ Prenit Pokhrel, Department of Oral and Maxillofacial Surgery, Kantipur Dental College, Kathmandu, Nepal; 'Bijendra Raj Raghubanshi, Department of Microbiology, KIST Medical College Teaching Hospital, Kathmandu, Nepal; ${ }^{5}$ Amshuman Shrestha; ${ }^{6}$ Binod Raut, Residents, Department of Pharmacology, Kathmandu Medical College Teaching Hospital, Kathmandu, Nepal.

\section{Abstract}

Background: Restoration of carious teeth is required to preserve anatomy, function and aesthetics of a tooth. Proper restoration of carious teeth is paramount for the prevention of progression of a dental caries so as to obviate the need for root canal treatment. Location, extent, type, duration and cost play the major roles for the selection of a dental filling material.

Objective: This study was set to know the preference of dentists for the selection of filling materials for different tooth cavities.

Methods: This was cross-sectional observational study carried out at Kantipur Dental College and KIST Medical College for a period of six months. Pre-structured questionnaires were distributed to the dentists who were in dental practice and collected questionnaires were analyzed for the results. Data were compiled, entered and analyzed using Microsoft Excel 2007 and Epi Info 2000. Yates corrected Chi square test was used wherever applicable and level of significance was set at $<0.05$.

Results: Out of 65 questionnaires distributed to the dental practitioners, 57 (87.7\%) questionnaires were returned. Composite was the material of choice as the restorative material for all kinds of tooth cavities except for class $V$ for which glass ionomer cement was the main choice (52.6\%). After composite, dental amalgam was second most preferred material for posterior tooth restorations. Order of preference for filling materials for posterior restorations were: composite (52.6\%), dental amalgam (47.4\%), miracle mix (68.3\%; $\mathrm{P}<0.05)$ and glass ionomer cement $(42.1 \%)$. Majority of practitioners $(78.9 \%$, $\mathrm{P}<0.05$ ) opined that strength and durability of restorative material is the main guiding factor for the selection of the filling material for posterior tooth restorations. Additionally, dental amalgam had higher $(68 \%, \mathrm{P}<0.05)$ patient satisfaction with respect to cost and longevity or durability and was associated with less tiring and time consuming procedure (84\%; $\mathrm{P}<0.05)$ on dentists' view.

Conclusion: Majority of dentists opined that composite is the more preferred filling material for both anterior and posterior tooth restorations. For posterior tooth cavities (mainly for class I, II and VI) after composite, the order preference for filling materials was amalgam, miracle mix and glass ionomer cement.

Key words: Dental caries, Dentistry, Filling material, Nepal, Tooth restoration

\section{Address for correspondence}

Dr. Keshab Raj Paudel

Assistant Professor

Department of Pharmacology

Kathmandu Medical College Teaching Hospital,

Kathmandu, Nepal

E-mail: keshabpaudel@gmail.com

\section{INTRODUCTION}

Prevalence of dental caries ranges from $13 \%$ to $96 \%$ in different parts of the world in different age groups ${ }^{1-4}$. Dental caries should be restored properly to prevent pulpal involvement and to restore the anatomy, function and aesthetics of the tooth structure. Different tooth restorative materials are available to the dental practitioners. However depending upon tooth type, 
location and extent of dental caries, age and sex of the practitioner and the patient may affect the selection of filling material ${ }^{5-8}$.

There are two types of tooth restorations: direct and indirect. Direct tooth restorations involve dental filling materials and usually require single sitting. Indirect tooth restorations involve inlays, onlays, crowns, bridges, etc. and usually require at least two sittings. This study is concerned with direct tooth restorations. Composite and dental amalgam are most commonly used materials for direct tooth restorations. However, other materials such as glass ionomer, resin ionomer, miracle mix, etc. are also used for direct tooth restorations ${ }^{9}$. These materials have their own advantages and disadvantages in relation to cavity preparations, strength, durability, aesthetics, secondary caries formation and cost $t^{7,10-13}$.

Interestingly, there are some debates regarding the use of one of the most common material i.e. the dental amalgam as minuscule amount of elemental mercury vapour may be released during mixing and which is toxic because dental amalgam fillings are created by mixing elemental mercury (43\% to $54 \%$ ) and an alloy powder composed mainly of silver, tin and copper. The U.S. Food and Drug Administration and other public health organizations have studied the safety profile of amalgam restorations and reached to the conclusion that "no valid scientific evidence has shown that amalgams cause harm to patients with dental restorations, except in rare cases of allergy"14. The World Health Organization gave the similar conclusion ${ }^{15}$ and the U.S. Centers for Disease Control states that "at present, there is scant evidence that the health of the vast majority of people with amalgam is compromised, nor that removing amalgam fillings has a beneficial effect on health"16. Similarly, no other public organization has found evidence to support discontinuation of the material. So, no governmental organization in any country places restriction on dental amalgam ${ }^{9}$. So, it is in dental practice all over the world.

For anterior tooth restorations, consideration of aesthetics is most important factor during tooth restoration. So, only the tooth coloured materials can be used for anterior tooth cavities. However, for posterior tooth restorations, other factors like strength and durability are also paramount as posterior teeth have to bear with masticatory load. Dental practitioner's clinical skill and experience is one of the factors which is significantly involved for the selection of filling material that finally leads to clinical success and patient's satisfaction $^{17}$.
This study aimed to find out the following objectives based on the dental practitioners' view ; (1) the choice of material for different tooth cavities in permanent teeth i.e. class I, class II, class III, class IV, class V and class $\mathrm{VI},(2)$ order of preference of materials for posterior tooth restorations, (3) factor(s) which determine(s) the selection of filling materials, (4) patient's satisfaction in terms of cost and durability or longevity, and (5) less time consuming and tiring procedure.

\section{METHODS}

This was a cross-sectional observational study. Sixty five pre-structured questionnaires were distributed to the dental practitioners at KIST Medical College and Kantipur Dental College in Kathmandu valley, Nepal in 2013 after obtaining institutional ethical clearance and informed verbal consent from the participants. Fifty seven completely filled questionnaires were returned and evaluated for the study. A total of nine close-ended and one open-ended questions were included in each questionnaire to know the materials of choice for different permanent tooth cavities, factors that govern the selection of restorative material, less technique sensitive filling material, material with patient's satisfaction visa-vis cost and durability or longevity and first, second, third and fourth material of choice for posterior tooth restorations. Data were compiled, entered and analyzed using Microsoft Excel 2007 and Epi Info 2000. Yates corrected Chi square test was used wherever applicable and level of significance was set at $<0.05$.

\section{RESULTS}

Out of 65 questionnaires distributed to the dental practitioners, 57 (87.7\%) questionnaires were returned by the respondents with 30 (52.6\%) females and 27 $(47.4 \%)$ males with average of five years in dental practice. The mean age of respondents was 31.7 years (Mean $\pm \mathrm{SD}=31.7 \pm 2.2$ ). Composite was the material of choice as the restorative material for all kinds of tooth cavities except for class $\mathrm{V}$ for which glass ionomer cement was main choice (52.6\%). And, this selection was significant for class I, IV and VI with $100 \%$ selection for class III cavities. After composite, dental amalgam was second most preferred for posterior tooth restorations (Table 1).

Dentists' order of preference for filling materials for posterior restorations showed as follows; composite (52.6\%) as first choice, dental amalgam (47.4\%) as second choice, miracle mix (68.3\%; $\mathrm{P}<0.05)$ as third choice and glass ionomer cement (42.1\%) as fourth choice (Table 2). 
Majority of practitioners $(78.9 \%, \mathrm{p}<0.05)$ opined that strength and durability of restorative material is the main guiding factor for the selection of the filling material for posterior tooth restorations (Figure 1). Additionally, dental amalgam had higher $(68 \%, \mathrm{p}<0.05)$ patient satisfaction with respect to cost and longevity or durability as per the practitioners' responses (Figure 2). Similarly, significant number of dentists $(84 \% ; \mathrm{p}<0.05)$ responded that dental amalgam restoration was associated with less tiring and time consuming procedure (Figure 3 ).

Table 1: Dentists' view on materials of choice for different tooth cavities.

\begin{tabular}{|c|c|c|c|c|c|c|}
\hline Material & Class I & Class II & Class III & Class IV & Class V & Class VI \\
\hline Composite & 39 (68.4\%) & 30 (52.6\%) & $57(100 \%)$ & $54(94.7 \%)$ & 27 (47.4\%) & 45 (78.9\%) \\
\hline Dental amalgam & $18(31.6 \%)$ & $24(42.1 \%)$ & & & & $6(10.5 \%)$ \\
\hline Miracle mix & & $3(5.3 \%)$ & & & & $4(7.0 \%)$ \\
\hline Glass ionomer cement & & & & $3(5.3 \%)$ & 30 (52.6\%) & \\
\hline No response & & & & & & $2(3.6 \%)$ \\
\hline
\end{tabular}

$\mathrm{P}$ value $<0.05$ for class I, class IV and class VI

Table 2: Dentists' view on order of preference for restorative materials for posterior tooth restorations (mainly for class I, II and VI).

\begin{tabular}{|c|c|c|c|c|}
\hline Material & First choice & Second choice & Third choice & Fourth Choice \\
\hline Composite & $30(52.6 \%)$ & $21(36.8 \%)$ & & \\
\hline Dental amalgam & $27(47.4 \%)$ & $27(47.4 \%)$ & & $3(5.3 \%)$ \\
\hline Miracle mix & & $6(10.5 \%)$ & $39(68.3 \%)$ & $5(8.7 \%)$ \\
\hline Glass ionomer cement & & & $6(10.5 \%)$ & $24(42.1 \%)$ \\
\hline Bonded amalgam & & $3(5.3 \%)$ & $3(5.3 \%)$ & $4(7.0 \%)$ \\
\hline Zinc phosphate & & & $3(5.3 \%)$ & $9(15.8 \%)$ \\
\hline Silicate & & & $3(5.3 \%)$ & \\
\hline Zinc polycarboxylate & & & & $2(3.6 \%)$ \\
\hline No response & & & $3(5.3 \%)$ & $10(17.5 \%)$ \\
\hline
\end{tabular}

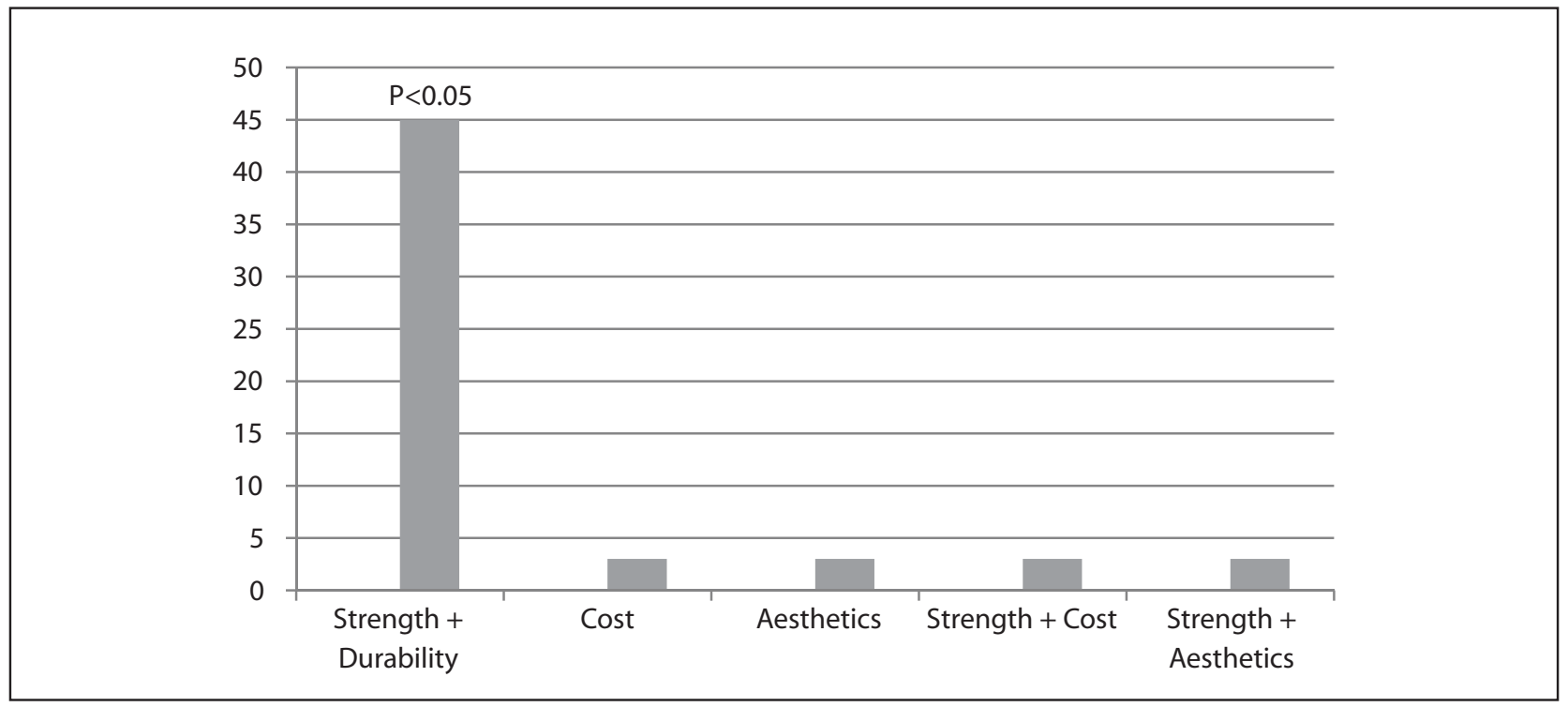

Figure 1: Dentists' view on different factors for the selection of restorative materials for posterior tooth rstorations (mainly for I, II and VI). 


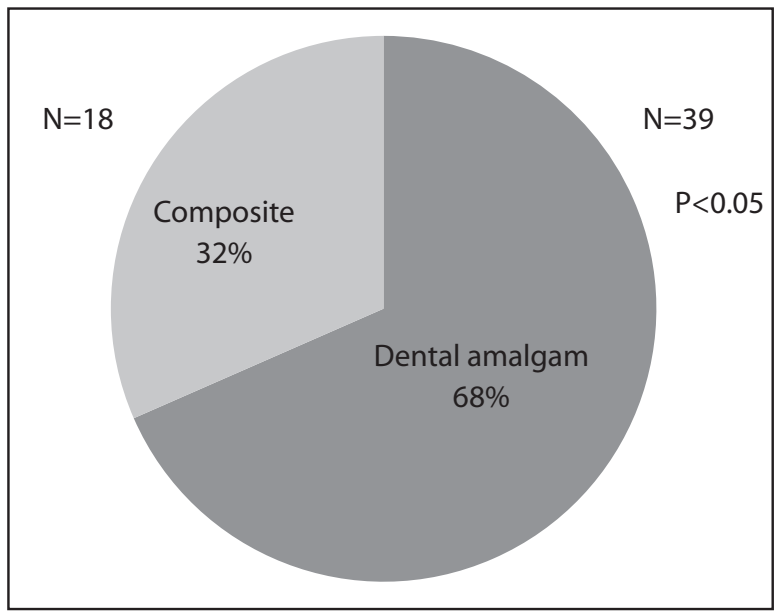

Figure 2: Dentists' view on patient's satisfaction with respect to cost and durability.

\section{DISCUSSION}

Majority of dental practitioners $(68.4 \%, \mathrm{p}<0.05)$ preferred composite as material of choice for class I and II followed by amalgam. Similarly, it was the material of choice in class III (100\%), class IV (94.7\%) and class VI (78.9\%) cavities. However, glass ionomer cement was the material of choice in class $\mathrm{V}$ (52.6\%) followed by composite (47.4\%). In previous findings, $61 \%$ of dental practitioners opined that amalgam use had decreased over the last five years, $75 \%$ felt posterior composite use had increased. Similarly, majority of practitioners preferred posterior composite restorations in load bearing areas in few previous studies. So, these findings may suggest that the choice of restorative material is influenced by clinical indications and the patient's aesthetic demands $s^{5,12}$. In anterior tooth restorations (mainly class III and IV) aesthetics is of the prime importance and the main concern. Tooth colored materials especially composite is the main choice and selection of direct filling materials is quite restricted. So this article focuses on the findings of this study mainly on the posterior tooth restorations and materials used.

For posterior tooth restorations, composite was the first material of choice followed by amalgam, miracle mix and glass ionomer cement in the order of preference. Though composite and amalgam are more commonly preferred, these materials have certain disadvantages which should be considered along with caries characteristics before the selection of the material. Some inherent disadvantages with composite fillings encompass polymerisation shrinkage, deficient marginal adaptation, higher wear rates, defective contact points leading to food impaction

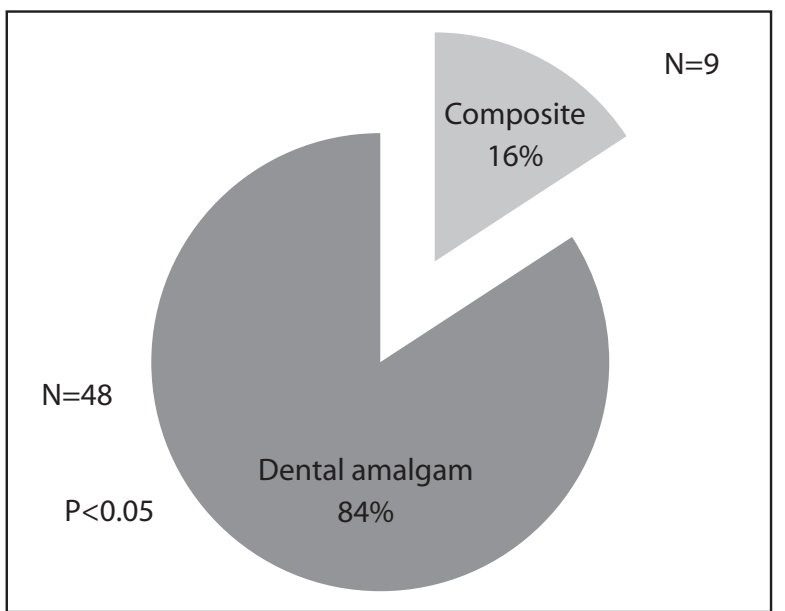

Figure 3: Dentists' view on filling materials with different percentages of selection for less tiring and time consuming procedure.

and insufficiently converted composite at the bottom of the cavity $^{10}$. Similarly, weaknesses for amalgam restoration include the need for retentive cavities at the cost of healthy tooth substance, weakening of the tooth's strength, the risk of fracture of remaining tooth substance as the result of the cavity preparation, and the lack of adhesion between amalgam and tooth substance. With above factors in mind, restoring a tooth in its original build-up or structure along with esthetics and function within the oral cavity is the main basis for the tooth restoration. Hence, the use of composite appears to be more obvious than restoring with amalgam ${ }^{10}$. Previous finding also have shown that use of composite for posterior tooth restorations has been increased with acceptable clinical performance and success $s^{5,6,11-13,18}$. However, despite advances in aesthetic dentistry, U.S. dentists still are placing amalgam on posterior teeth with carious lesions. Amalgam was used more often than composite in older patients, who may have had deeper carious lesions ${ }^{19}$. Dentist's personal skills and clinical knowledge may become more significant when planning treatment for complex restorative cases and selection of material ${ }^{17}$. Hence, there is still a place for dental amalgam in modern restorative dentistry ${ }^{10}$ which is in consonant with the present findings.

Though reports regarding the use of miracle mix could not be found in the literature, in the present findings, it is the third material of choice for the posterior tooth restorations which might be due to its direct bonding to the tooth structure and much tooth structure needs not be sacrificed unlike amalgam restoration. Glass 
ionomer cement was the fourth choice and this may be due to the fact that it is preferred in small occlusal primary caries and in non-load bearing areas i.e. class V. Additionally, few respondents opined that bonded amalgam, zinc polycaboxylate cement, zinc phosphate and silicate cement may also be used for posterior tooth restorations as some alternatives. However, present findings suggest that composite and dental amalgam, and to some extent miracle mix, are the main restorative materials for the posterior tooth cavities.

Based on the present data, majority of dentists $(p<0.05)$ would give first priority to the strength and durability or longevity as far as selection of material for posterior tooth restoration was concerned and considered that dental amalgam had higher patient's satisfaction in terms of cost and longevity. And, this finding is in agreement with the previous findings which are as follows; the survival of dental amalgam restorations is twice as high as for composite fillings ${ }^{10}$. Similarly, Kopperud SE et al ${ }^{12}$ reported that the mean annual failure rate was $2.9 \%$ for composite restorations and $1.6 \%$ for amalgams. For composite restorations, secondary caries was the most common reason for replacement (73.9\%), followed by loss $(8.0 \%)$, fracture $(5.3 \%)$, and marginal defects $(2.4 \%)^{12}$. Another similar study showed that the median longevity of replaced restorations was 16 and six years for amalgam and composite respectively. Significantly longer longevity was observed for replaced restorations executed by more experienced dentists ${ }^{11}$. Clinically, durability or longevity of the restorations depend on many factors such as quality of restorations, the material properties, the handling characteristics, and patient factors like oral hygiene and bruxism. Similarly, the complexity of the restoration is generally considered important for longevity ${ }^{20}$, but this view has been challenged ${ }^{21}$. Previous study had predicted that median longevity for single and three surface amalgam restorations to be ten and eight years respectively. Similarly, median longevity of single and three surfaces composite was seven and four years respectively. Moreover, cost for composite was found to be two and half times more than for dental amalgam in long-term cost analysis study ${ }^{22}$. Based on these facts, amalgam restoration has more longevity and less expensive than composite restoration similar to views obtained in this study. Similarly, majority of dentists opined that dental amalgam restoration is less tiring and time consuming procedure $(p<0.05)$ than composite restoration. This may be due to individual practitioner's concerns over technique sensitive procedure for composite, particularly with regard to moisture control, placement and control of polymerisation shrinkage ${ }^{13}$. Despite above findings, when it came to the selection of material for posterior cavities, majority of them selected composite as the material of first choice. We need to explore proper reasons for this contradictory finding in the future studies. However, possible explanation is that it may be due to the aesthetic demand of the patients and/or gender of the patients as female patients are aesthetically more demanding. Additionally, other clinical (type of tooth, extent of decay, load bearing area) and practitioner's factors (clinical skill, experience, confidence, attitude, gender of the practitioner $)^{5,7,12}$ may be responsible for this contradictory finding.

Limitations of present study involve as follows; extent of tooth decay, type of posterior tooth i.e. molar or premolar, maxillary or mandibular, paths and areas of occlusal forces and patient's preference have not taken into consideration while conducting the study ${ }^{8}$ as dentist and practice properties (gender of practitioner, years since graduation and type of practice), patient properties (sex, race, age and dental insurance status); and caries characteristics (tooth location and surface, preoperative and postoperative lesion depth) are associated with the type of restorative material used ${ }^{19,23}$. So, in this study, results are based entirely on the dentists' individual perception and experience and represent their perspective on different filling materials for different tooth cavities in permanent teeth.

\section{CONCLUSION}

On dentists' view, composite is the more preferred filling material for both anterior and posterior tooth restorations. For posterior tooth cavities (mainly for class I, II and VI) after composite, the order preference for filling materials was amalgam, miracle mix and glass ionomer cement. Strength and durability are the main factors that govern the selection of restorative materials for posterior tooth cavities. Patient's satisfaction with regard to cost and durability or longevity was more with amalgam than composite. Tooth restoration with dental amalgam is less tiring and time consuming procedure. Although dental amalgam has more longevity and less cost, and entails technically less sensitive procedure than composite, composite is more preferred for posterior tooth restorations than amalgam. 


\section{REFERENCES}

1. Yee R, Sheiham A. Caries experience of 5-6 year-old and 12-13 year-old schoolchildren in central and western Nepal. Intl Dent J. 2002;52:453-60.

2. Perinetti G, Varvara G, Esposito P. Prevalence of dental caries in school children living in rural and urban areas: results from the first region-wide Italian survey. Oral Health Prev Dent. 2006;4:199-207.

3. Lo EC, Holmgren CJ, Hu DY, Wan HC. Dental caries status and treatment needs of 12-13-year-old children in Sichuan province, southwestern China. Community Dent Health. 1999;16:114-6.

4. Warren JJ, Cowen HJ, Watkins CM, Hand JS. Dental caries prevalence and dental care utilization among the very old. J Am Dent Assoc. 2000;131:1571-9.

5. Gilmour AS, Evans P, Addy LD. Attitudes of general dental practitioners in the UK to the use of composite materials in posterior teeth. Br Dent J. 2007;202(12):32.

6. Gordan VV, Riley JL, Worley DC, Gilbert GH. Restorative material and other tooth-specific variables associated with the decision to repair or replace defective restorations: findings from The Dental PBRN. J Dent. 2012;40(5):397-405.

7. Correa MB, Peres MA, Peres KG, Horta BL, Barros AD, Demarco FF. Amalgam or composite resin? Factors influencing the choice of restorative material. J Dent. 2012;40(9):703-10.

8. Vidnes-Kopperud S, Tveit AB, Gaarden T, Sandvik $L$, Espelid I. Factors influencing dentists' choice of amalgam and tooth-colored restorative materials for Class II preparations in younger patients. Acta Odontol Scand. 2009;67(2):74-9.

9. American Dental Association. Dental filling facts [Internet]. [cited 2012 Oct 5]. US: American dental association (ADA). available from: www.ada.org.

10. De Moor R, Delmé K. Black or white--Which choice for the molars? Part 2. Which does one choose for the restoration of posterior teeth: amalgam or composite? Rev Belge Med Dent. 2008;63(4):135-46.

11. Sunnegårdh-Grönberg $K$, van Dijken JW, Funegård $U$, Lindberg A, Nilsson M. Selection of dental materials and longevity of replaced restorations in Public Dental Health clinics in northern Sweden. J Dent. 2009;37(9):673-8.

12. Kopperud SE, Tveit AB, Gaarden T, Sandvik L, Espelid I. Longevity of posterior dental restorations and reasons for failure. Eur J Oral Sci. 2012;120(6):53948.

13. Mackenzie L, Burke FJ, Shortall AC. Posterior composites: a practical guide revisited. Dent Update. 2012;39(3):211-2.

14. U.S. Food and Drug Administration (FDA). Consumer Update: Dental Amalgams. US: FDA; 2002 Dec 31.

15. World Health Organization (WHO). WHO Consensus Statement on Dental Amalgam. Geneva: WHO; 1997 Sep.

16. U.S. Centers for Disease Control (CDC). Fact Sheet: Dental Amalgam Uses and Benefits. US: CDC; updated 2005 Feb 2.

17. Alani A, Bishop K, Djemal S. The influence of specialty training, experience, discussion and reflection on decision making in modern restorative treatment planning. Br Dent J. 2011;210(4):4.

18. Andrade AK, Duarte RM, Silva FD, Batista $A U$, Lima KC, Pontual ML, et al. Clinical evaluation of nanofill and nanohybrid composite in Class I restorations: a 12-month randomized trial. Gen Dent. 2012;60(4):255-62.

19. Makhija SK, Gordan VV, Gilbert GH, Litaker MS, Rindal DB, Pihlstrom DJ, et al. Practitioner, patient and carious lesion characteristics associated with type of restorative material: findings from The Dental Practice-Based Research Network. J Am Dent Assoc. 2011;142(6):622-32.

20. Maryniuk GA, Kaplan SH. Longevity of restorations: survey results of dentists' estimates and attitudes. J Am Dent Assoc. 1986;112:39-45.

21. Smales RJ. Longevity of cusp-covered amalgams: survival after 15 years. Oper Dent. 1991;16:17-20.

22. Mjor IA. Problems and benefits associated with restorative materials: side effects and long-term cost. Adv Dent Res. 1992;6:7-16.

23. Lubisich EB, Hilton TJ, Ferracane JL, Pashova HI, Burton B. Association between caries location and restorative material treatment provided. J Dent. 2011;39(4):302-8. 